\title{
Young consumers in fast food restaurants: technology, toys and family time
}

\author{
by Kellershohn, J., Walley, K. West, B. and Vriesekoop,
} $F$.

Copyright, Publisher and Additional Information: This is the author accepted manuscript. The final published version (version of record) is available online via Emerald Publishing.

Please refer to any applicable terms of use of the publisher.

DOI: https://doi.org/10.1108/YC-08-2017-00731 
Young Consumers in Fast Food Restaurants: Technology, Toys and Family Time

\begin{tabular}{|r|l|}
\hline Journal: & Young Consumers \\
\hline Manuscript ID & YC-08-2017-00731.R1 \\
\hline Manuscript Type: & Research Paper \\
\hline Keywords: & $\begin{array}{l}\text { Ethnography, Family meal, Fast Food, Restaurant, Technoference, children } \\
\text { and food }\end{array}$ \\
\hline \multicolumn{2}{|c}{} \\
& $\begin{array}{c}\text { SCHOLARONE } \\
\text { Manuscripts }\end{array}$ \\
\hline
\end{tabular}




\section{Young Consumers in Fast Food Restaurants: Technology, Toys and Family Time}

\section{Introduction}

Restaurant meals, once an occasional family treat, now represent a significant amount of the daily nutrients children consume. The amount of food eaten by families, away from home, has been increasing for over 40 years (USDA, 2016). Food-at-Home refers to total grocery expenditures for food prepared by the consumer in their home, while Food-Away- from-Home (FAFH) includes all meals at fast food and full service restaurants, take-out, delivery, concession stands, buffets, cafeterias, and vending machines (USDL, 2015). In American households, 50\% of the total food budget goes to FAFH (USDA, 2016), and over one third of American children consume fast food on any given day (Castro et al., 2016).

This growing trend is not unique to US households. In Canadian households, $29 \%$ of the total food budget is spent on FAFH (Statistics Canada, 2015), in the United Kingdom it is $28 \%$ of the total food budget (Office for National Statistics, 2016) and in Australia, FAFH is $27 \%$ of the total food budget (Australia Bureau of Statistics, 2006).

This trend, driven by convenience and the growing array of FAFH options, is unlikely to reverse itself in the near future. The current generation of young consumers is growing up in a culture of frequent family dining moments outside of the home. It is important to understand what these family dining experiences entail and how they may shape current food dining behaviours, in order to address the evolving needs of young consumers. Using an ethnographic approach, allows for the discovery of patterns in human behaviour in a real-life environment.

This study contributes to the literature about family consumer behavior and meal time interactions with an ethnographic study that specifically explores these behaviours inside of a fast food restaurant. Using unobtrusive direct observation, structured observational data was recorded on the behaviours of naturally occurring groups of families with at least one child $\geq 2$ to $\leq 12$ years old, dining in fast food restaurants in Toronto, Canada. Emergent themes were grouped into three main categories: technology use, toys, and family behaviours.

\section{Family use of technology}

The year 2017 is the ten-year anniversary of the introduction of the iPhone. The use of mobile technology, such as iPhones and tablets, in eating establishments is now common place. This study was conducted in Canada, a country with a high prevalence of technology, internet access and smart phones. In a recent survey of 39 countries, the Canadian millennial population had the third highest percentage of smart phone ownership (94\%) and is forecast to continue to grow over the next five years (Statista, 2017).

With the millennial generation accounting for the majority of new births (Pew Research Centre, 2017), understanding how this tech-savvy generation includes technology in common family interactions is important, both in terms of how parents interact with their children, and in terms of how these young consumers are being raised with the presence of technology as a part of their life. 
Prior ethnographic research, examining mobile technology use and children in fast food restaurants, noted that parents focused on their digital world rather than on their children during the restaurant visit (Radesky et al., 2014). While for some families, technology may create new opportunities for family interactions, other families may experience 'technoference' (McDaniel, 2013; McDaniel and Radesky, 2017) (i.e., where technology is found to interfere with family interactions). Technoference is not unidirectional. It can be children ignored by parents and/or parents ignored by children as they focus on their tablets and smartphones. The increasing role of technology in the family dining experience is a key area of interest for this observational study, as there is currently a gap in our knowledge on the prevalence of technology use during the family fast food dining visit.

\section{Toys and Fast Food Restaurants}

Toys, included in the purchase of a child's meal, are often vilified in the popular press for playing a potential role in the growth of fast food consumption by children. However, the toy is a part of the fast food experience for many families. Published scientific research has shown that the toy is not a top reason for fast food choices, rather, the top three reasons adults choose fast food for their family are: (1) rapid service, (2) convenient location and (3) good tasting food (Rydell et al., 2008). While the toy is not listed as one of the top three decision drivers, the multi-million dollar industry based on food marketing through toys continues to come under increased scrutiny and there are opposing opinions (Anzman-Frasca et al., 2017). When toys are included in a child's meal, $49 \%$ of parents report the presence of the toy did not enter into their purchase decision "at all" (Boutelle et al., 2011); while for some parents, there is displeasure at the addition of toys to food orders (VicHealth, 2015).

In some cases, government intervention has influenced the presence of toys in a child's meal. For example, the introduction of a local ordinance in San Francisco, California banned the inclusion of free toys in meals (Otten et al., 2014), while in two other counties of California, an ordinance was passed that toys could only be included in a child's meal that met a well-accepted nutritional standard (Otten, 2014).

There are also positive aspects described by parents, such as making their child happy or allowing the parent time to enjoy their meal (VicHealth, 2015). To make the toy better able to compete with more appealing technology-based alternatives, some fast food restaurants now include a code or access to a smartphone app with the toy, so that the child receives both a physical toy and access to a virtual game.

Companies, government organizations, and families are all experiencing a change in the role of the toy in a child's meal (Bakan, 2012). Therefore, our understanding of the toy's role during the fast food dining experience requires updating.

\section{Family Behaviours in Fast Food Restaurants - 'Third Place'}

First coined by sociologist Ray Oldenberg in 1989, the term 'Third Place' refers to a location for everyday social interactions that provides a 'home away from home' role (Oldenburg, 1989). If the first two places for a consumer are home, and work, the 'third place' is growing in its role for consumers, and includes public spaces such as coffee shops and fast food restaurants, as well as virtual communities (Wang et al., 2017). With young consumers consuming as much as one-third of their meals in fast food restaurants, fast food restaurants have become a 'third place' for families, a 'home away from home' in which their natural family behaviours may be observed and requires research. 


\section{Study Perspective}

There is little research on family dining behaviours inside of the fast food restaurant. Some research has been conducted on the importance, in terms of customer satisfaction, of reducing wait times in lines at fast food restaurants (Chou and Liu, 1999; Iqbal et al., 2012). Children who dine at a restaurant at least once a month typically already know what they will order before arrival (Castro et al., 2016). To date, observational research has not adequately addressed the behaviour of parents and children in fast food restaurants in terms of ordering time, dining time and play time in indoor play places. How families spend their time in this type of restaurant, the level of engagement of children, and what family interactions take place within the restaurant setting is of interest for understanding the consumer behaviour of a modern family dining experience, especially in terms of technology, toys and family time. This study was conducted as a part of a larger ongoing study examining how and why families make decisions in fast food restaurants. This study focused on understanding the observable behaviours of families dining in fast food restaurants.

\section{Methodology}

This study used a direct, unobtrusive observational approach, with both structured and unstructured data collection methodology to examine family dining (for parties with at least one child between the ages of 2 and 12 years old) in fast food restaurants, in Toronto, Canada, during the six-month period from summer 2016 to January 2017.

\section{Observation Site and Participant Selection}

Toronto, Ontario, is the largest city in Canada, with a multicultural population of over six million people. Both fast food restaurants that were chosen as sites for the study belong to one of the largest international fast food chains and were selected based on seating arrangements that allowed for the inconspicuous observation of customer orders, as well as an environment with a high frequency of family visits and free Wi-Fi. The restaurants had a drive through option, free and easily accessible parking for customers, an indoor play area, and a dine-in area with a mix of seating options (both booths and tables with chairs) accommodating approximately 100 customers.

The chosen restaurants were located in ethnically diverse middle-class neighbourhoods, with a high density of families with school-age children. Two large television screens were hung on the walls, playing a 24/7 news channel. Free crayons and colouring pages were available upon request from the restaurant staff, with no purchase requirement. There was a fixed display of children's toys, positioned near the front counter, at the eye-level of a child. The displayed toys accompanied the purchase of the child's meal and were also available for individual purchase. The toys were themed on a popular animated kidstargeted movie that was in theatres during the time of the research. There were digital menu boards and customers could order directly from a restaurant staff member at the front counter, or by using selfservice digital kiosks. The indoor play area, with signage identifying it as appropriate for children age 312 , was a separate room with glass interior walls that faced into the dining area of the restaurant. The indoor play areas featured crawl tubes, a play structure and slides. Inside the play room there was additional seating, separate from the main dining area, for adults who wished to sit closer to their children at play. Approximately one-third of the seats in the main dining area also had visibility to the interior of the indoor play area. The restaurants, in which the research was conducted, belong to an 
international fast food chain, and the design is reflective of fast food restaurants not just within Canada but in many areas of the world.

\section{Observational Method (Direct, Unobtrusive, Structured)}

At each visit, the researchers ordered a beverage or a snack and took a seat where they could unobtrusively observe families and take notes. The researchers' activities were intended to be subtle and not out of place for the environment, and the researchers noted that they did not feel noticed by the customers or by the restaurant staff. Restaurant managers and staff were not informed that a study was being conducted.

\section{Stage 1 (before receiving the food)}

During stage 1, 200 family order transactions were observed over 24 days in the summer of 2016, during the lunch hours of $11.00 \mathrm{am}$ to 1:30 pm, a peak time for family visits. Dining parties of two to six people, with at least one adult and at least one child (estimated age between $\geq 2$ and $\leq 12$ years), were targeted for observation in terms of behaviour during the time prior to eating the food. The researchers visually followed a single transaction from the customers' entry into the restaurant to when they received their food order. A structured observation instrument with a closed-ended coding scheme was used, allowing for quantification of key behaviours. The observation instrument was developed and refined by the lead ethnographer, during a three-day pilot test, prior to the main field word. A lead researcher and a secondary researcher trained by the lead conducted the research. Researchers used a digital timer to record how long families waited in line prior to ordering, how long they spoke to the restaurant employee during the ordering process and how long they waited to receive their meal. In addition, the researchers also recorded if a child's meal was ordered (identified by the distinctive packaging of the child's meal) and customer demographics (number of people in the transaction; gender; gender of the person placing the order; age range - adults: under 30, 30-50, 50+; children between the ages of 2 and 12 years) and observable behaviour of family members such as presence and usage of technology (e.g., smartphones, portable gaming systems, etc.) and parent-child interactions. The researchers were also encouraged to take additional field notes in an unstructured manner, should they observe behaviours that were not captured in the structured form. After the entire observation was complete, the researcher tracked the next adult/child group that entered the restaurant.

Stage 2 (after receiving the food)

During the second stage of the study, the researchers observed 100 families (with at least one child aged $\geq 2$ to $\leq 12$ years old) dining inside the fast food restaurant. This research was conducted during the winter school break in January 2017, over a ten-day period, during the lunch hours of 11.00 am to 1:30 $\mathrm{pm}$, peak family visit time. The lead researcher was the same as in the first stage of research, but additional secondary researchers were added to the team for the second phase of research, due to the complexity of tracking family behaviours over extended periods of time. Researchers visually followed a single transaction from when the food order was received, to when the family left the restaurant. $A$ team of three researchers, supporting the lead ethnographer, were strategically placed throughout the restaurant, to allow for continuous tracking of families throughout their visit. If family members moved between restaurant sections, the researchers (communicating via text message) maintained the line of vision for continuous observational monitoring, while staying anonymous. 


\section{Analysis of Data}

At the end of each day's observations, field jottings were expanded into full-length field notes (example field notes are included in the results section). In addition to focusing on specific categories identified in the structured observational form, emerging themes of behaviour and experiences from open observations were reviewed.

Quantitatively, a structured observational approach was used for the following: visit ordering time, total visit length, the presence of technology and timed use of technology, the presence of a child's meal with toy, whether the child played with the toy, timed toy play, whether the child visited the indoor play room and timed indoor play.

Observational data were entered and analysed using the statistical software package IBM SPSS Version 23.0. Descriptive statistics, $t$-tests and ANOVAs were performed to describe family restaurant behaviours and to identify possible differences between sub-groups.

\section{Results and Discussion}

\section{Family use of Technology \\ Ordering Food}

In the restaurants, customers had the opportunity to use technology when ordering their food.

Kiosks - The restaurants had digital self-service ordering kiosks, where customers could order food without waiting in line to speak with an order-taker at the front counter. However, the kiosk orders were not broadly adopted by families, with less than $6 \%$ of the families observed using the kiosk ordering system. The researchers noted that the kiosks were positioned at adult height and if a child wanted to place their own order at a kiosk, the parent likely would have to physically lift the child, for the child to use the kiosk.

Smart Phones and Ordering - Despite a Canadian consumer population with a high density of smart phones and advances in technologies enabling restaurants to target consumers through tools such as geofencing and push-notifications to smart phones (Catalyst, 2015), very little personal technology was observed being used during the food ordering process and $94 \%$ of adults in the party did not visibly interact with their smart phones, or other technology, at any point during the food ordering process. Only $2 \%$ of children used any form of technology (smart phones, tablets, portable gaming systems, ear phones plugged into digital media) at this time. The researchers noted that while the families ordering their food were being observed during peak customer traffic times in the restaurants (lunchtimes on Friday, Saturday and Sunday), the line-ups still moved quickly and efficiently suggesting that perhaps there was insufficient time for customers to be distracted by personal technology during this process.

\section{Technoference and the Family Dining Experience}

Once the food had been received, and the family moved into the dining area and settled into their dining rituals, the presence of technology became much more prevalent. The current generation of children are growing up in a digital world, with an estimated one-third of children having used a device 
such as a smart phone or tablet before the age of one and the majority of children have used mobile devices by age two (Sifferlin, 2015). These children will likely have a digital thread that runs through their entire lives, shaping how they interact with family members and their environment.

\section{Children}

Restaurant-provided digital entertainment.

For the children that had the child's meal with toy purchase, the restaurant-provided toy also included a code that would allow the customer to download a child's e-game related to the toy, to a smart phone or tablet. However, no families were observed using the code to activate and play the restaurantprovided game on a smart phone or tablet during their time in the dining area. While children were observed playing a variety of games on smart phones and tablets, these games appeared to have been games that they brought with them and not the game provided by the restaurant.

\section{Personal technology and digital entertainment}

The presence of technology during the family dining experience was very prevalent. The researchers observed that it was common for a family to bring technology such as a tablet, an iPad or a handheld gaming system into the restaurant specifically for their child to use. For example, child-sized headphones that the child wore to independently watch a video playing on a tablet while they were eating. The use of some form of technology during the visit was observed for $40 \%$ of the children, with use averaging 14 minutes ( $30 \%$ of the total dining time).

\section{Adults}

While sometimes adults used technology when dining with their child, the key time for adults to use their personal technology was while the child was playing in the indoor play area, with $70 \%$ of observed adults spending time using technology, such as a smart phone or a tablet, at this time. Of the $30 \%$ of adults that did not use technology while waiting for their children to play or eat, half of these adults used the time to talk to another adult in their party, while the other half watched the TVs that were mounted in the restaurant or read books or the free newspapers provided by the restaurant.

For most, any interaction with screen time came from time spent with personal screens (smart phones, tablets, iPads) that the customers brought with them into the restaurant. The restaurants had flat screen TVs playing 24/7 news channels in the restaurants, but engagement with the TVs was limited. Only $15 \%$ of adults and $5 \%$ of children were observed spending any time watching the restaurant TVs.

During the dining experience, $25 \%$ of the families included an adult who used their mobile technology to take at least one photo of the meal event, including photos of the food, photos of the child, selfies, and group photos. The use of technology to capture the dining experience was not unexpected, given the millennial consumer's love of photographing their food. It is estimated that as high as $69 \%$ of millennial consumers take a photo or video of their meal before eating (Maru/Matchbox, 2016).

Technoference, technology-based interference in parent-child interactions, is a growing part of the family dining experience. Of the 100 families observed dining, researchers noted that technoference appeared to be a frequent occurrence during family meals. Children's engagement in technology appeared to lead to less interaction with their parent(s), and when the adult was engaged in using technology, they appeared to be less responsive to the child. 


\section{Child's Meal and Restaurant-Provided Toys}

Since toys are often criticized in the popular press for playing a potential role in influencing children to consume more fast food, field researchers were instructed to include in their structured field notes specific observations about the role that the free toy played in the family dining experience, both during the ordering process and during the dining experience.

In the restaurant, there were three options available to children that might be considered restaurantprovided toys: (1) free crayons and colouring sheets were available upon request to any customer, with no purchase requirement, (2) the child's meals came with a toy and (3) the child's meals came in a box that had games and images printed on the box for the child.

There was little use of the free crayons and colouring sheets. Only $7 \%$ of families used these, and that was only when on one of the field days a restaurant manager had walked around the dining area actively passing out sheets and crayons to families. No family was observed requesting these from the order counter, although the lack of observed use of these sheets and crayons may stem from a lack of awareness of their availability.

During the field research, the toys available in the restaurant were characters from a popular children's movie, in theatres at the time, which was one of the top 10 grossing box office movies of the year. While the restaurant layouts included an eye-level display of toys that accompanied the child's meal options, fewer than $5 \%$ of the children were observed looking at, or interacting with, the toy display either as a part of the ordering process or during the dining experience.

Nearly 7 in 10 families (68\%) purchased a dedicated child's meal, which included a free toy and a custom box for the meal. The distinctive packaging of the child's meal made it easy for the researchers to observe when this was purchased, and to see if the child interacted with the packaging. While there were games on the box for the child's amusement, only $20 \%$ of children spent any time playing or looking at the box. For most families, the meal was unpacked and the box was immediately set to the side. It was often used as a repository for garbage from the meal.

The inclusion of a toy in the child's meal did not mean that children were necessarily permitted to play with the toy during the restaurant visit. For $22 \%$ of the children, an adult removed the toy from the box and tucked it away out of sight (for example into a bag or purse) and the toy remained there during the entire visit.

For the $78 \%$ of children that did interact with the toy during their visit, researchers noted that for many families there appeared to be a rule or negotiation associated with when the child could play with the toy (for example, some parents could be overheard saying that the child could play with the toy only after they had eaten their meal). Of the children observed, $18 \%$ played with the toy before eating, $40 \%$ played with the toy while eating and $45 \%$ played with the toy after eating. These were not mutually exclusive moments, for example, some children played with the toy before, during and after the meal. Of those that played with the toy, on average, they played with the toy for 10 minutes (minimum 2 minutes, maximum 27 minutes). 


\section{Family Behaviours}

\section{Third Place}

The restaurant appeared to serve the role of a 'third place' (a substitute home), with what seemed to be regular and local customers who were familiar with the specific location. The fast food restaurants appeared to provide neutral ground, where societal status did not seem to be very important and there was a casual hominess, in which customers treated the space as a home away from home as noted earlier.

For many families, the restaurant was used as a common meeting place, where they could socialize with other families. It was a place for the children to play together in the play room, while the adults interacted without the need to pay close attention to the children. A summary of the results from the enumerated family behaviours is illustrated in Figure 1.

Brembeck (2005), in a study of fast food restaurant meals in Sweden, has suggested that a 'proper' family meal in a fast food restaurant for many parents is an effortless way of upholding family life, and creating 'family' and 'home' in new ways. Thus, some of the behaviours of the families observed in this study, such as the presence of technology during meal times, should not necessarily be viewed as unique to a fast food restaurant, but today are potentially indicative of common family dining behaviours beyond fast food restaurants.

\section{Family Interactions During Food Ordering}

During the ordering process, $69 \%$ of children remained with their adult, with varying degrees of involvement in the ordering process. Prior to ordering, $66 \%$ of adults spoke with the child at least once before placing the food order. While placing the order, $12 \%$ of children were involved in placing the order, speaking directly to the restaurant employee taking the order. The food ordering process was noted to be a very neutral experience overall, and fewer than $5 \%$ of the children were noted as being visibly unhappy (crying or yelling).

The demographics of the adults (number of adults, gender, and age) were examined to see whether specific subgroups were more likely to involve their child in the ordering process. No statistically significant subgroup differences were detected.

\section{Empirical Measurements of Family Ordering Times}

Researchers observed the families during lunch hours on Fridays, Saturdays and Sundays, as these days of the week reflect the busiest times for families in restaurants, and as such, the measured times could reasonably be expected to be on the high end of what a typical family might experience. Families visiting during non-peak times might have a faster ordering experience.

\section{Pre-order Time}

The average customer time, from the moment the family entered the restaurant to when they first spoke to the order taker, averaged 1 minute and 39 seconds. Customers spent a comparable amount of time regardless of party size, gender, ethnicity or number of children. 


\section{Time to Place the Order}

The average order transaction time was 1 minute and 17 seconds. All observed attributes were analysed to determine which, if any, might influence order time. Three main elements were identified as statistically significant in impacting order time.

(i) Size of Party: As the number of people in the party increased, the amount of time to order increased. When there were two or more adults in the party, order time increased by an additional 19 seconds $(+27 \%)$. With parties of three of more children, order time increased by 41 seconds ( $+53 \%)$.

(ii) Customer Age. As the observed age of the adults in the party increased, the length of time to order increased as well. Transactions with adults estimated to be under the age of 50 typically took 1 minute and 14 seconds, while transactions with adults estimated to be over the age of 50, took an average of 1 minute and 28 seconds ( $+13 \%)$.

(iii) Ordering a Child's Meal Bundle. Including a child's meal (identified by the distinctive packaging) in the ordering process increased the average order time from 69 seconds to 82 seconds $(+19 \%)$.

\section{Time to receive the order}

The average wait time to receive a meal was 2 minutes and 53 seconds. No statistically significant subgroups based on observed attributes were identified.

\section{Family Behaviours During Dining}

\section{Eating}

The ethnographic research was based on naturally occurring family visits, but the observed family groups did not necessarily order food for every individual in their party. Five percent of children did not have food that appeared to be ordered specifically for them and they were observed sharing food with an adult and $14 \%$ of adults did not appear to have ordered food for themselves. In addition, $14 \%$ of families brought food into the restaurant from an outside source and consumed that food in the restaurant (e.g., a box of donuts, juice boxes, plastic containers of cheerios cereal).

Often an adult unpackaged and/or arranged the food on the table for the family. For example, this included pulling the food out of the packaging, arranging it in front of the child, and on $32 \%$ of the occasions it included at least one time where an adult hand was feeding the child, for example holding the burger for them to bite or holding their drink cup for them. While there was a self-serve beverage fountain in the restaurant, only $11 \%$ of children were observed using it to fill their own drink cups.

The researchers observed that the adults frequently used this food set-up time to provide direction to the child on behaviour expectations, for example tucking a toy away before the child ate the food, or putting the packaging to the side and identifying it as a receptacle for waste.

Meal time did not appear to be a time for extensive conversations. Many of the families ate in near silence or with minimal interaction. Eating was automatic and appeared disengaged in nature. Often, dining occurred in stages. Either the child ate first, and then went to play while the adult(s) ate, or the adult(s) ate while the child played in the play room and later the child ate. Eating in stages often meant that when the child ate first, the parent later 'finished' the food the child left behind. Approximately 
one-third of the children ate at a different time than their parents. As a result of staggered eating times, modelling desirable eating behaviours is challenging (Ayadi and Bree, 2010).

Food tended not to be shared among family members, with one notable exception, which was the shared consumption of french fries, and the observed familial habits that seemed to accompany this. For some families, the communal approach to fry eating involved placing the fry order in the centre of the dining table, so that all members of the family had equal access to the fries. Some $37 \%$ of adults were observed eating fries from the child's order and $23 \%$ of the children were observed eating fries from the adult's food order. Taking food from family members that was not french fries was less frequent, with $28 \%$ of adults eating from the food ordered for the children (i.e., food that was not french fries), although this was often after the child declared themselves finished eating, and $12 \%$ of children were observed eating some of the non-french fry food that the adults had ordered. Often the taking of french fries from one another appeared to be in kind-hearted jest or a thoughtful way to share food without perceived injustice (for example a large order of french fries might have $50+$ french fries in it, making it easy to share a few fries with a family member without a perceptible loss of food).

\section{Use of the Play Area}

The restaurants included an indoor play area, with signage indicating it was meant for children age 3 to 12 years old. During the food ordering process, no children were observed to be playing in the indoor playground while their accompanying adult ordered food.

While there was optional seating ( 2 tables and 4 chairs) inside of the indoor play room, where adults could sit and supervise the children as they played, these seats were most often empty. Rarely did adults move from the table they had dined at, into the indoor play area to watch their children closely. More often, there appeared to be an assumption that if the child was in the play area, no additional supervision was required. With the large glass windows on the interior of the indoor play area, there was visibility into the indoor play area from approximately one-third of the main dining area, however, the windows muted the sounds of the children.

Supervision of the children in the play room was minimal. While approximately two-thirds of the seating in the main dining area did not provide sight into the indoor play room, this lack of sight line did not appear to influence whether or not the child went into the play room. Most often, parents remained seated at the table in the main dining area, while children went to play in the indoor play area unsupervised.

The indoor play room was a strong draw for the children, with $65 \%$ of children spending time there and averaging 33 minutes in the play room (minimum 3 minutes to maximum 99 minutes). The approach to balancing play time and eating varied by family. Of the children that spent time in the play area, $55 \%$ spent time in the play area prior to eating and $36 \%$ went back and forth to the play area during the meal. Of the children that visited the play area, $81 \%$ of those children visited the play area after finishing their meal. Play was not limited to within the indoor play area as children were also observed conducting free play (neither on the climbing structure nor with a toy) during their visit, averaging 4 minutes of free play in the dining area in addition to time spent dining and in the indoor play area.

The researchers also noted that during the 10 days of field research, they observed two families who came to the restaurant for the express purpose of allowing their children to play in the indoor play area. 
During their visits, they ordered neither food nor drink from the restaurant. Field notes also included two families that spent so much time in the restaurant that they consumed two distinct meal orders during their one visit, giving their children extended time to play both in the dining area and play area, between the meals.

\section{Other Activities}

While the child ate or played in the indoor playground, the adults were observed conducting a wide variety of activities that one might not associate with restaurant based activities but are reflective of how the fast food restaurant has taken on the role of a 'third space' for families. Observed activities included (but were not limited to): conducting a business meeting with a laptop, interviewing someone for a job, working on homework, playing chess, watching an entire movie on a tablet, sleeping on a bench, and clipping and filing fingernails.

\section{Field Notes}

Extensive field notes were gathered during the research. The field notes included a structured component in which researchers noted observations on technology, toy usage and dining behaviours as well as an unstructured component, where researchers recorded other observations, which were later grouped into themes during the analysis. An example of a field note from each of the broad categories identified from the research is included in Table 1.

\section{Conclusions}

The study investigated the behaviours of families in fast food restaurants, both their ordering and inrestaurant dining experience. Twelve years ago, Brembeck (2005) suggested that fast food meals provide an opportunity for parents to have a 'proper' family meal with their children. Indeed, fast food restaurants appear to have taken on a 'third place' role for families, offering not only fast, and convenient dining, but also a public space in which to gather and spend time. Elements of how the observed families dined together may illustrate common behaviours in a sizeable proportion of today's family meals. The presence of technoference for personal entertainment had not yet become mainstream during the time that Brembeck studied families in fast food restaurants. The rise of technology has led to a shift in dining practices, such as the intrusion of technology during the meal. With food consumed away from home on the rise, understanding how families dine outside of the home will continue to grow in importance, especially in terms of technology, toys and family time.

The main results indicate that:

\section{- Technology}

- While mobile technology was largely absent during the ordering process, once the families moved to the dining area, both children and adults were frequently observed using technology in the restaurant. As a result, technoference appeared to be present during the family dining experience for many families in the fast food restaurants, with $40 \%$ of children using technology while with their family.

\section{- Toys}


- Children spent more time playing with technology they brought from home (14 minutes) than playing with a restaurant provided toy (10 minutes).

\section{- Family Time}

- Meal ordering was a quick and functionally driven experience, with minimal adult/child interaction, averaging less than 6 minutes from the time the family entered the restaurant to when they had received their complete food order.

- French fries provided a shared dining experience for families.

- While the children spent time in the indoor playground (average 33 minutes), adults used the time for independent activities (70\% used their smart phone).

- The fast food restaurant was treated as a 'third place', with many observed activities unrelated to traditional restaurant dining.

\section{Limitations and Future Perspectives}

Canadian food dining culture may be different from that observed in other countries, and as such, these results have to be considered within the Canadian context. Canadians have one the highest global rates of smart phone usage and internet connectivity and may, therefore, be a bellwether of future consumer behaviour in countries with rapidly growing smart phone penetration, as well as countries with a similar frequency of family fast food consumption. What is unknown is whether this change in behaviour resulting from the prevalence of personal technology has plateaued or if it will continue to increase in the coming years.

A limitation of this study is that it focused exclusively on in-restaurant behaviours. There is no visibility of the parent/child interaction prior to entering the restaurant, nor visibility to behaviours after they leave the restaurant. Therefore, the toy and associated e-game may play a larger role than what was observed in-restaurant.

This research relied on observed behaviours and on the subjective abilities of the ethnographers. Future research considerations should include follow-up interviews with families to provide a greater depth of information about their experience. Other future research should also include restaurant locations without an indoor play area, to examine if this would change the amount of time spent by children and adults using personal mobile technology. 


\section{References}

Anzman-Frasca, S., Folta, S.C., Glenn, M.E., Jones-Mueller, A., Lynskey, V.M., Patel, A.A., Lisa, L.T. and Lopez, N.V. (2017), "Healthier children's meals in restaurants: an exploratory study to inform approaches that are acceptable across stakeholders", Journal of Nutrition Education and Behavior, Vol. 49 No. 4, pp. 285-295.

Australian Bureau of Statistics, (2006), "Australian social trends", available at: http://www.abs.gov.au/AUSSTATS/abs@.nsf/DetailsPage/4102.02006?OpenDocument (accessed 30 July, 2017)

Ayadi, K. and Bree, J. (2010), "An ethnography of the transfer of food learning within the family", Young Consumers, Vol. 11 No. 1, pp. 67-76.

Bakan, J. (2012), Childhood Under Siege: How Big Business Targets Your Children. Simon and Schuster, New York, NY.

Boutelle, K. N., Fannin, H., Newfield, R. S. and Harnack, L. (2011), "Nutritional quality of lunch meal purchased for children at a fast-food restaurant", Childhood Obesity, Vol. 7 No. 4, pp. 316-322.

Brembeck, H. (2005), "Home to McDonald's: upholding the family dinner with the help of McDonald's", Food, Culture and Society, Vol. 8 No.2, pp.215-226.

Castro, I. A., Williams, C. B., Madanat, H., Pickrel, J. L., Jun, H. J., Zive, M., Gahagan, S. and Ayala, G. X. (2016), "Food ordering for children in restaurants: multiple sources of influence on decision making", Public Health Nutrition, Vol. 19 No. 13, pp. 2404-2409.

Catalyst (2015), "With growth comes change: the evolving mobile landscape in 2015", available at: http://catalyst.ca/2015-canadian-smartphone-market/ (accessed 30 July 2017)

Chou, C. Y. and Liu, H. R. (1999), "Simulation study on the queuing system in a fast-food restaurant", Journal of Restaurant and Foodservice Marketing, Vol. 3 No. 2, pp. 23-26.

Iqbal, Q., Whitman, L. E. and Malzahn, D. (2012), "Reducing customer wait time at a fast food restaurant on campus", Journal of Foodservice Business Research, Vol. 15 No. 4, pp. 319-34.

Maru/Matchbox (2016), "The future of food. Are you ready for the millennials?", available at: https://marumatchbox.com/resources/Ip-the-future-of-food-are-you-ready-for-the-millennials/ ( accessed 30 July, 2017)

McDaniel, B.T. (2013), "Technoference: Everyday intrusions and interruptions of technology in couple and family relationships", in Bruess, C.J. (Ed.), Family Communication in the Age of Digital and Social Media, Peter Lang Publishing, New York, NY, pp. 228-244.

McDaniel, B.T. and Radesky, J.S. (2017), "Technoference: Parent distraction with technology and associations with child behavior problems", Child Development, doi: 10.1111/cdev.12822 [Epub ahead of print]

Office for National Statistics (2016), "Statistical bulletin: Family spending in the UK: financial year ending March 2016", available at: 
https://www.ons.gov.uk/peoplepopulationandcommunity/personalandhouseholdfinances/expenditure/ bulletins/familyspendingintheuk/financialyearendingmarch2016 (accessed 30 July, 2017)

Oldenburg, R. (1989), The great good place: Café, coffee shops, community centers, beauty parlors, general stores, bars, hangouts, and how they get you through the day, Paragon House Publishers, New York, NY.

Otten, J.J. (2014), Food Marketing: Using Toys to Market Children's Meals. Healthy Eating Research, Minneapolis, MN, available at: http://healthyeatingresearch.org/wpcontent/uploads/2014/07/her marketing toys AUGUST 14.pdf (accessed 30 July, 2017)

Otten, J.J., Saelens, B.E., Kapphahn, K.I., Hekler, E.B., Buman, M.P., Goldstein, B.A., Krukowski, R.A., O'Donohue, L.S., Gardner, C.D. and King, A.C. (2014), "Impact of San Francisco's toy ordinance on restaurants and children's food purchases, 2011-2012", Preventing Chronic Disease, Vol. 11, p.E122.

Pew Research Centre (2017), "Pew Research Center analysis of National Center for Health Statistics data", available at: http://www.pewresearch.org/fact-tank/2017/01/03/more-than-a-millionmillennials-are-becoming-moms-each-year/ (accessed 30 July, 2017)

Radesky, J.S., Kistin, C.J., Zuckerman, B., Nitzberg, K., Gross, J., Kaplan-Sanoff, M., Augustyn, M. and Silverstein, M. (2014), "Patterns of mobile device use by caregivers and children during meals in fast food restaurants", Pediatrics, Vol. 133 No. 4, doi:10.1542/peds.2013-3703

Rydell, S. A., Harnack, L. J., Oakes, J. M., Story, M., Jeffery, R. W., and French, S. A. (2008), "Why eat at fast-food restaurants: reported reasons among frequent consumers", Journal of the American Dietetic Association, Vol. 108 No.12, pp. 2066-2070.

Sifferlin, A. (2015), "Research: 6-month-old babies are now using tablets and smartphones", Time (Health), 25 Apr, available at: http://time.com/3834978/babies-use-devices/) (accessed 30 July, 2017)

Statista (2017), "Is your cellphone a smartphone, such as an iPhone, a Blackberry or the like?" available at: https://www.statista.com/statistics/539409/smartphone-ownership-by-age-in-selected-countries/) (accessed 30 July, 2017)

Statistics Canada (2015), "Average household food expenditure, (Ontario)", available from: http://www.statcan.gc.ca/tables-tableaux/sum-som/l01/cst01/famil132g-eng.htm (accessed 30 July, 2017)

United States Department of Agriculture (USDA) (2016), “Food expenditures - United States Department of Agriculture, Economic Research", available at: https://www.ers.usda.gov/data-products/foodexpenditures.aspx (accessed 30 July 2017)

United States Department of Labour (USDL) (2015), "Glossary - consumer expenditure survey", available at: https://www.bls.gov/cex/csxgloss.htm (accessed 30 July 2017)

VicHealth (2015), "Fame and Shame awards: Not so happy: McDonald's not lovin' Fame and Shame awards". 8 Dec. 2015. [On-line] available at: https://www.vichealth.vic.gov.au/media-andresources/media-releases/not-so-happy-mcdonalds-not-lovin-fame-and-shame-awards (accessed 30 July 2017) 
Wang, Y., Deng, Q. and Ji, S. (2017), “Applying third place theory in mobile social media research: The physical-virtual integration", CONF-IRM 2017 Proceedings. 4, available at:

http://aisel.aisnet.org/confirm2017/4 (accessed 30 July 2017) 


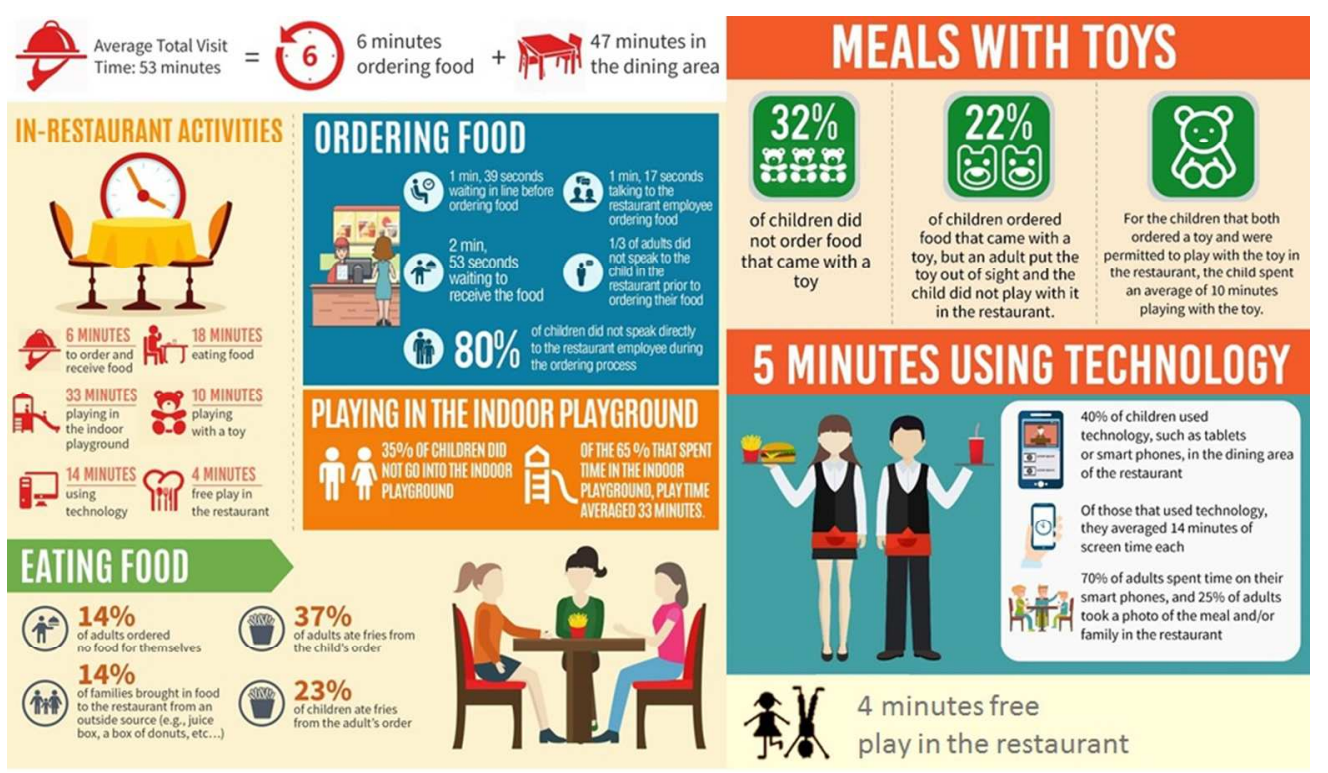

A summary of the observed family behaviours in the fast food restaurant.

$266 \times 154 \mathrm{~mm}(96 \times 96 \mathrm{DPI})$ 


\begin{tabular}{|c|c|}
\hline Theme & Example Field Notes \\
\hline $\begin{array}{l}\text { Children and } \\
\text { Technology }\end{array}$ & $\begin{array}{l}\text { Both children used technology (cell phones) while at the table waiting for mom to return } \\
\text { with the meal, and they used phones while mom was setting the food out. Little/no } \\
\text { conversation during the meal. The youngest boy kept one of the phones out during the } \\
\text { meal and was the most distracted and he only ate food that he could eat with one hand } \\
\text { (juice and hash browns), while his older brother watched the phone screen but still ate. } \\
\text { Entire table was silent. When the meal was finished, mom asked children if they were } \\
\text { ready to go (based on the fact that they were using the technology, not because they } \\
\text { were still eating). }\end{array}$ \\
\hline $\begin{array}{l}\text { Adults and } \\
\text { Technology }\end{array}$ & $\begin{array}{l}\text { Grandmother used her phone from the time they sat down until they left ( } 31 \text { minutes). } \\
\text { Dad used the phone while waiting for the food order but put the phone away once his } \\
\text { wife came back with the meals. Most conversation happened between adults. Food was } \\
\text { cut and unwrapped for children and mom shared some pieces of her pancake with the } \\
\text { toddler. Eldest son had some of the dad's juice, son ate half of the mom's muffin, she ate } \\
\text { the rest. Mom only used phone when boys went to the play area in contrast to the father } \\
\text { and grandmother, who were using their phones before and during meal (with children } \\
\text { present). The eldest son was distracted with the toy for most of the time, but when he } \\
\text { saw another child with a different family using an iPad to watch videos, he stood over } \\
\text { their shoulders to watch for a while. }\end{array}$ \\
\hline $\begin{array}{l}\text { Limited } \\
\text { Conversations }\end{array}$ & $\begin{array}{l}\text { Child was distracted by phone, didn't touch the food at all and the toy was left in packet. } \\
\text { Adults were having their own conversation. Food was set out for the child but she didn't } \\
\text { eat it for } 20 \text { minutes. Her eyes never left the phone screen even when she grabbed a few } \\
\text { fries to eat and to drink juice. She tried to play with the box but no one helped her so she } \\
\text { gave up. Child didn't eat more than } 5 \% \text { of her meal before leaving for the play room. }\end{array}$ \\
\hline Toy/Box & $\begin{array}{l}\text { Youngest child interested in toy pre-meal, looked at it and picked it up but didn't take it } \\
\text { out of the wrapper. Dad took both toys and kept them to the side. Relatively silent meal. } \\
\text { Dad hand-fed the yogurt to youngest child, and child only ate when dad hand fed her. } \\
\text { Shared moment between dad and children when he showed them how to play with the } \\
\text { toy. Children played with toy even while dad was cleaning up to get them ready to leave. }\end{array}$ \\
\hline Shared Fries & $\begin{array}{l}\text { Adult (male) and child (female) had two orders of fries as a part of their meal. Both orders } \\
\text { of fries were placed in the middle of the table where they could both reach them and } \\
\text { they shared both orders. }\end{array}$ \\
\hline Staged Eating & $\begin{array}{l}\text { Children started in the play room. When the children's food arrived, adults did not call } \\
\text { them to eat but waited for them to notice, and meanwhile they ate their own food. } \\
\text { Adults didn't pay a lot of attention to the children when they were in the play room but } \\
\text { occasionally looked into the room to make sure they were OK. After finishing their own } \\
\text { meals, the parents set out food for the children. They removed the empty boxes from the } \\
\text { table, taking away the chance to play with the box. }\end{array}$ \\
\hline 'Third Place' & $\begin{array}{l}\text { Child paid little attention to the food and was focused on the play room. The adult } \\
\text { (female) didn't push the child to eat and instead waited for him to notice that there was } \\
\text { food and to leave the play room to come and eat. While the child was in the play room, } \\
\text { the adult cut her nails, had a quick nap, and chatted with other adults in the restaurant. } \\
\text { Adult did not supervise the child in the play room. }\end{array}$ \\
\hline
\end{tabular}




\section{Response to Reviewers}

The authors thank the reviewers for their insightful and very helpful comments. All issues have been carefully addressed in the revised paper and detailed below and a file showing the insertions/deletions has also been submitted.

\section{Response to Reviewer 1}

\section{General Comments}

A well and interesting paper written by the authors. However, there are some amendments you guys need to do so that readers are not confused, and it reflects high quality papers in Young Consumers. Well done Author Response: Thank-you. Your recommendations have been addressed below and in the revised version of the paper. We appreciate your advice to strengthen the paper and the time you took to provide the very thoughtful and helpful feedback.

\section{Additional Notes}

1. Originality: The paper provides an interesting ethnographic view on family dining in fast food restaurants.

Author Response: Thank-you.

2. Relationship to Literature: This paper demonstrates understanding of relevant literature in the field and the introductory section is clear. Using unobtrusive direct observation, the ethnographers were able to capture interesting patterns of family behaviour in the fast food restaurants.

However, the researchers need to rephrase the purpose of study (see page 2, line 17). As it stands, "...examining how and why families make decisions in fast food restaurants", the statement does not reflect the actual study been done and furthermore interviews with parents are necessary to determine their decisions. A more relevant statement for the purpose of study is on page 11 , line 46, "...understanding how families dine outside...".

Author Response: Thank-you for your comments. This study is an element of a larger research study, examining how and why families make decisions in fast food restaurants. We agree that interviews with parents are a key element to understanding how the decisions are made $\rightarrow$ in fact this is part of a different study we are currently working on. To better reflect the role of this specific study, as per your recommendation, the purpose of this study has been revised in the paper. "This study focused on understanding the observable behaviours of families dining in fast food restaurants." 
4. Results: As described on page 5, line 13 the descriptive statistics, cross-tabulations, t-tests and ANOVA were used for data analyses, but the results presented were mainly reflective of descriptive statistics. If ANOVA was used, which is comparing means, the authors should briefly describe the results. Similarly, this applies cross-tabulations results. T-tests is acceptable since it was mentioned on page 8 , line 41 that there is no statistical difference between subgroup.

Page 11 , line 7 - What is puzzling here is, "...during their one visit (a breakfast and later a lunch),...", if the observations were conducted between 11.00 am to $1.30 \mathrm{pm}$, how did the authors know the first order was breakfast? It is common for family to order two separate meals in different time. Perhaps the portion was too little or the family ate more. Authors should change delete the words breakfast and lunch.

\section{Author Response: Thank-you for your comments.}

The comment "No statistically significant subgroup differences were detected." refers to both the t-tests and ANOVAs that were performed. ANOVA tests were used for any analysis with more than 2 subgroups. The note on cross-tabulations has been removed from the paper, as these tables were not used in the final report.

The two families who had both breakfast and lunch were a bit of a puzzle to us as well, and we debated whether not to include them in the final report. As we could observe the meals, we could see them first eat a meal that was egg-based and later a meal with hamburgers. As well, we overheard the restaurant staff speak with them, and say "Oh, you must really like it here. You're having breakfast and lunch here". The comment about breakfast and lunch has now been removed to avoid confusion for the readers.

5. Implications for research, practice and/or society: This paper has identified the versatility of ethnographic study in busy environment of fast food restaurants and the authors have implied the change of family behaviour in fast food restaurants compared with Brembeck's (2005) study 12 years ago.

Author Response: Thank-you. We believe that the change in family behaviour over the past 12 years is notable. 
6. Quality of Communication: This paper is well expressed and structured.

Author Response: Thank-you.

\title{
Response to Reviewer 2
}

Thank-you for your thoughtful and very helpful comments and insights. We believe that we have addressed all concerns from your notes in the responses and we will now have a clearer paper thanks to your help.

\section{General Comments}

Is there a difference between eating take-outs at home and receiving delivery at home and eat at home and the rest of FAFH which is eat out both the process of cooking and the eating ecology? That and the need for at least mentioning theoretical ethnographic work is all that I would want to add

Author Response: Thank-you for your comments.

Food at Home is the total (food-based) expenditures from grocery stores and food prepared by consumers. While FAFH covers a larger range of foods, including when Take-out or Food Delivery (such as pizza) is eaten at home. The definition of FAFH has been included in the paper's introduction and it has been expanded to further clarify and reflect this.

Additional information has been added to the introduction to address why ethnography was the chosen approach for this study.

\section{Additional Notes}

1. Originality: I think this is a novel and fascinating study

\author{
Author Response: Thank-you.
}

2. Relationship to Literature: There isn't much literature on this as far as I know and what they use is good enough

\section{Author Response: Thank-you.}

3. Methodology: It is a mixture of numerical analysis and observations and I'm wondering if there is a theoretical stance they could take that informs the interesting research

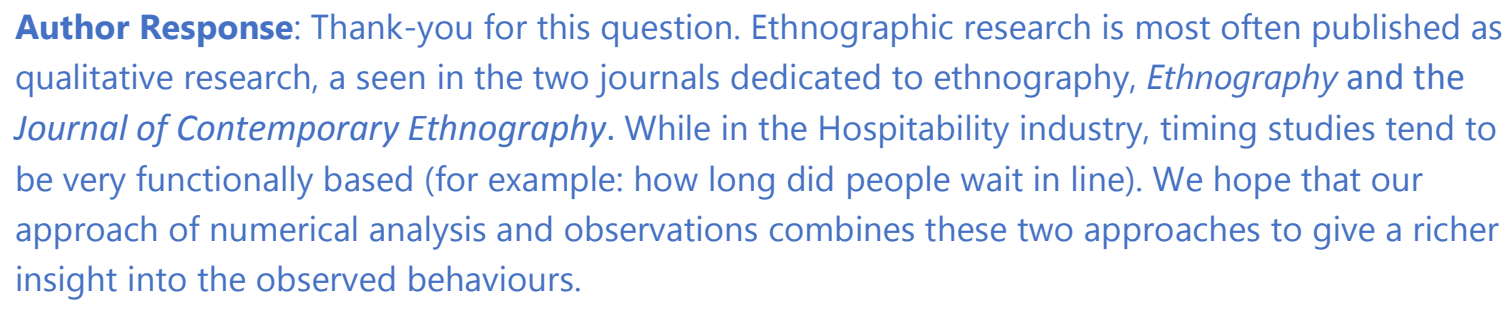
qualitative research, a seen in the two journals dedicated to ethnography, Ethnography and the Journal of Contemporary Ethnography. While in the Hospitability industry, timing studies tend to be very functionally based (for example: how long did people wait in line). We hope that our approach of numerical analysis and observations combines these two approaches to give a richer insight into the observed behaviours. 
4. Results: Yes.

Author Response: Thank-you.

5. Implications for research, practice and/or society: Useful.

Author Response: Thank-you.

6. Quality of Communication: Absolutely OK - nicely seen to Author Response: Thank-you. 


\section{Young Consumers in Fast Food Restaurants: Technology, Toys and Family Time}

\section{Introduction}

Restaurant meals, once an occasional family treat, now represent a significant amount of the daily nutrients children consume. The amount of food eaten by families, away from home, has been increasing for over 40 years (USDA, 2016). Food-at-Home refers to total grocery expenditures for food prepared by the consumer in their home, while Food-Away-from-Home (FAFH) includes all meals at fast food and full service restaurants, take-out, delivery, concession stands, buffets, cafeterias, and vending machines (USDL, 2015). In American households, 50\% of the total food budget goes to FAFH (USDA, 2016), and over one third of American children consume fast food on any given day (Castro et al., 2016).

This growing trend is not unique to US households. In Canadian households, $29 \%$ of the total food budget is spent on FAFH (Statistics Canada, 2015), in the United Kingdom it is $28 \%$ of the total food budget (Office for National Statistics, 2016) and in Australia, FAFH is $27 \%$ of the total food budget (Australia Bureau of Statistics, 2006).

This trend, driven by convenience and the growing array of FAFH options, is unlikely to reverse itself in the near future. The current generation of young consumers is growing up in a culture of frequent family dining moments outside of the home. It is important to understand what these family dining experiences entail and how they may shape current food dining behaviours, in order to address the evolving needs of young consumers. Using an ethnographic approach, allows for the discovery of patterns in human behaviour in a real-life environment.

This study contributes to the literature about family consumer behavior and meal time interactions with an ethnographic study that specifically explores these behaviours inside of a fast food restaurant. Using unobtrusive direct observation, structured observational data was recorded on the behaviours of naturally occurring groups of families with at least one child $\geq 2$ to $\leq 12$ years old, dining in fast food restaurants in Toronto, Canada. Emergent themes were grouped into three main categories: technology use, toys, and family behaviours.

\section{Family use of technology}

The year 2017 is the ten-year anniversary of the introduction of the iPhone. The use of mobile technology, such as iPhones and tablets, in eating establishments is now common place. This study was conducted in Canada, a country with a high prevalence of technology, internet access and smart phones. In a recent survey of 39 countries, the Canadian millennial population had the third highest percentage of smart phone ownership (94\%) and is forecast to continue to grow over the next five years (Statista, 2017).

With the millennial generation accounting for the majority of new births (Pew Research Centre, 2017), understanding how this tech-savvy generation includes technology in common family interactions is 
important, both in terms of how parents interact with their children, and in terms of how these young consumers are being raised with the presence of technology as a part of their life.

Prior ethnographic research, examining mobile technology use and children in fast food restaurants, noted that parents focused on their digital world rather than on their children during the restaurant visit (Radesky et al., 2014). While for some families, technology may create new opportunities for family interactions, other families may experience 'technoference' (McDaniel, 2013; McDaniel and Radesky, 2017) (i.e., where technology is found to interfere with family interactions). Technoference is not unidirectional. It can be children ignored by parents and/or parents ignored by children as they focus on their tablets and smartphones. The increasing role of technology in the family dining experience is a key area of interest for this observational study, as there is currently a gap in our knowledge on the prevalence of technology use during the family fast food dining visit.

\section{Toys and Fast Food Restaurants}

Toys, included in the purchase of a child's meal, are often vilified in the popular press for playing a potential role in the growth of fast food consumption by children. However, the toy is a part of the fast food experience for many families. Published scientific research has shown that the toy is not a top reason for fast food choices, rather, the top three reasons adults choose fast food for their family are: (1) rapid service, (2) convenient location and (3) good tasting food (Rydell et al., 2008). While the toy is not listed as one of the top three decision drivers, the multi-million dollar industry based on food marketing through toys continues to come under increased scrutiny and there are opposing opinions (Anzman-Frasca et al., 2017). When toys are included in a child's meal, $49 \%$ of parents report the presence of the toy did not enter into their purchase decision "at all" (Boutelle et al., 2011); while for some parents, there is displeasure at the addition of toys to food orders (VicHealth, 2015).

In some cases, government intervention has influenced the presence of toys in a child's meal. For example, the introduction of a local ordinance in San Francisco, California banned the inclusion of free toys in meals (Otten et al., 2014), while in two other counties of California, an ordinance was passed that toys could only be included in a child's meal that met a well-accepted nutritional standard (Otten, 2014).

There are also positive aspects described by parents, such as making their child happy or allowing the parent time to enjoy their meal (VicHealth, 2015). To make the toy better able to compete with more appealing technology-based alternatives, some fast food restaurants now include a code or access to a smartphone app with the toy, so that the child receives both a physical toy and access to a virtual game.

Companies, government organizations, and families are all experiencing a change in the role of the toy in a child's meal (Bakan, 2012). Therefore, our understanding of the toy's role during the fast food dining experience requires updating.

\section{Family Behaviours in Fast Food Restaurants - 'Third Place'}

First coined by sociologist Ray Oldenberg in 1989, the term 'Third Place' refers to a location for everyday social interactions that provides a 'home away from home' role (Oldenburg, 1989). If the first two places for a consumer are home, and work, the 'third place' is growing in its role for consumers, and includes public spaces such as coffee shops and fast food restaurants, as well as virtual communities 
(Wang et al., 2017). With young consumers consuming as much as one-third of their meals in fast food restaurants, fast food restaurants have become a 'third place' for families, a 'home away from home' in which their natural family behaviours may be observed and requires research.

\section{Study Perspective}

There is little research on family dining behaviours inside of the fast food restaurant. Some research has been conducted on the importance, in terms of customer satisfaction, of reducing wait times in lines at fast food restaurants (Chou and Liu, 1999; lqbal et al., 2012). Children who dine at a restaurant at least once a month typically already know what they will order before arrival (Castro et al., 2016). To date, observational research has not adequately addressed the behaviour of parents and children in fast food restaurants in terms of ordering time, dining time and play time in indoor play places. How families spend their time in this type of restaurant, the level of engagement of children, and what family interactions take place within the restaurant setting is of interest for understanding the consumer behaviour of a modern family dining experience, especially in terms of technology, toys and family time. This study was conducted as a part of a larger ongoing study examining how and why families make decisions in fast food restaurants. This study focused on understanding the observable behaviours of families dining in fast food restaurants.

\section{Methodology}

This study used a direct, unobtrusive observational approach, with both structured and unstructured data collection methodology to examine family dining (for parties with at least one child between the ages of 2 and 12 years old) in fast food restaurants, in Toronto, Canada, during the six-month period from summer 2016 to January 2017.

\section{Observation Site and Participant Selection}

Toronto, Ontario, is the largest city in Canada, with a multicultural population of over six million people. Both fast food restaurants that were chosen as sites for the study belong to one of the largest international fast food chains and were selected based on seating arrangements that allowed for the inconspicuous observation of customer orders, as well as an environment with a high frequency of family visits and free Wi-Fi. The restaurants had a drive through option, free and easily accessible parking for customers, an indoor play area, and a dine-in area with a mix of seating options (both booths and tables with chairs) accommodating approximately 100 customers.

The chosen restaurants were located in ethnically diverse middle-class neighbourhoods, with a high density of families with school-age children. Two large television screens were hung on the walls, playing a 24/7 news channel. Free crayons and colouring pages were available upon request from the restaurant staff, with no purchase requirement. There was a fixed display of children's toys, positioned near the front counter, at the eye-level of a child. The displayed toys accompanied the purchase of the child's meal and were also available for individual purchase. The toys were themed on a popular animated kidstargeted movie that was in theatres during the time of the research. There were digital menu boards and customers could order directly from a restaurant staff member at the front counter, or by using selfservice digital kiosks. The indoor play area, with signage identifying it as appropriate for children age 312 , was a separate room with glass interior walls that faced into the dining area of the restaurant. The 
indoor play areas featured crawl tubes, a play structure and slides. Inside the play room there was additional seating, separate from the main dining area, for adults who wished to sit closer to their children at play. Approximately one-third of the seats in the main dining area also had visibility to the interior of the indoor play area. The restaurants, in which the research was conducted, belong to an international fast food chain, and the design is reflective of fast food restaurants not just within Canada but in many areas of the world.

\section{Observational Method (Direct, Unobtrusive, Structured)}

At each visit, the researchers ordered a beverage or a snack and took a seat where they could unobtrusively observe families and take notes. The researchers' activities were intended to be subtle and not out of place for the environment, and the researchers noted that they did not feel noticed by the customers or by the restaurant staff. Restaurant managers and staff were not informed that a study was being conducted.

\section{Stage 1 (before receiving the food)}

During stage 1, 200 family order transactions were observed over 24 days in the summer of 2016, during the lunch hours of 11.00 am to $1: 30 \mathrm{pm}$, a peak time for family visits. Dining parties of two to six people, with at least one adult and at least one child (estimated age between $\geq 2$ and $\leq 12$ years), were targeted for observation in terms of behaviour during the time prior to eating the food. The researchers visually followed a single transaction from the customers' entry into the restaurant to when they received their food order. A structured observation instrument with a closed-ended coding scheme was used, allowing for quantification of key behaviours. The observation instrument was developed and refined by the lead ethnographer, during a three-day pilot test, prior to the main field word. A lead researcher and a secondary researcher trained by the lead conducted the research. Researchers used a digital timer to record how long families waited in line prior to ordering, how long they spoke to the restaurant employee during the ordering process and how long they waited to receive their meal. In addition, the researchers also recorded if a child's meal was ordered (identified by the distinctive packaging of the child's meal) and customer demographics (number of people in the transaction; gender; gender of the person placing the order; age range - adults: under 30, 30-50, 50+; children between the ages of 2 and 12 years) and observable behaviour of family members such as presence and usage of technology (e.g., smartphones, portable gaming systems, etc.) and parent-child interactions. The researchers were also encouraged to take additional field notes in an unstructured manner, should they observe behaviours that were not captured in the structured form. After the entire observation was complete, the researcher tracked the next adult/child group that entered the restaurant.

Stage 2 (after receiving the food)

During the second stage of the study, the researchers observed 100 families (with at least one child aged $\geq 2$ to $\leq 12$ years old) dining inside the fast food restaurant. This research was conducted during the winter school break in January 2017, over a ten-day period, during the lunch hours of 11.00 am to 1:30 $\mathrm{pm}$, peak family visit time. The lead researcher was the same as in the first stage of research, but additional secondary researchers were added to the team for the second phase of research, due to the complexity of tracking family behaviours over extended periods of time. Researchers visually followed a single transaction from when the food order was received, to when the family left the restaurant. A team of three researchers, supporting the lead ethnographer, were strategically placed throughout the restaurant, to allow for continuous tracking of families throughout their visit. If family 
members moved between restaurant sections, the researchers (communicating via text message) maintained the line of vision for continuous observational monitoring, while staying anonymous.

Analysis of Data

At the end of each day's observations, field jottings were expanded into full-length field notes (example field notes are included in the results section). In addition to focusing on specific categories identified in the structured observational form, emerging themes of behaviour and experiences from open observations were reviewed.

Quantitatively, a structured observational approach was used for the following: visit ordering time, total visit length, the presence of technology and timed use of technology, the presence of a child's meal with toy, whether the child played with the toy, timed toy play, whether the child visited the indoor play room and timed indoor play.

Observational data were entered and analysed using the statistical software package IBM SPSS Version 23.0. Descriptive statistics, fross-tabulations, t-tests and ANOVAs were performed to describe family restaurant behaviours and to identify possible differences between sub-groups.

\section{Results and Discussion}

\section{Family use of Technology \\ Ordering Food}

In the restaurants, customers had the opportunity to use technology when ordering their food. 
Kiosks - The restaurants had digital self-service ordering kiosks, where customers could order food without waiting in line to speak with an order-taker at the front counter. However, the kiosk orders were not broadly adopted by families, with less than $6 \%$ of the families observed using the kiosk ordering system. The researchers noted that the kiosks were positioned at adult height and if a child wanted to place their own order at a kiosk, the parent likely would have to physically lift the child, for the child to use the kiosk.

Smart Phones and Ordering - Despite a Canadian consumer population with a high density of smart phones and advances in technologies enabling restaurants to target consumers through tools such as geofencing and push-notifications to smart phones (Catalyst, 2015), very little personal technology was observed being used during the food ordering process and $94 \%$ of adults in the party did not visibly interact with their smart phones, or other technology, at any point during the food ordering process. Only $2 \%$ of children used any form of technology (smart phones, tablets, portable gaming systems, ear phones plugged into digital media) at this time. The researchers noted that while the families ordering their food were being observed during peak customer traffic times in the restaurants (lunchtimes on Friday, Saturday and Sunday), the line-ups still moved quickly and efficiently suggesting that perhaps there was insufficient time for customers to be distracted by personal technology during this process.

\section{Technoference and the Family Dining Experience}

Once the food had been received, and the family moved into the dining area and settled into their dining rituals, the presence of technology became much more prevalent. The current generation of children are growing up in a digital world, with an estimated one-third of children having used a device such as a smart phone or tablet before the age of one and the majority of children have used mobile devices by age two (Sifferlin, 2015). These children will likely have a digital thread that runs through their entire lives, shaping how they interact with family members and their environment.

\section{Children}

Restaurant-provided digital entertainment.

For the children that had the child's meal with toy purchase, the restaurant-provided toy also included a code that would allow the customer to download a child's e-game related to the toy, to a smart phone or tablet. However, no families were observed using the code to activate and play the restaurantprovided game on a smart phone or tablet during their time in the dining area. While children were observed playing a variety of games on smart phones and tablets, these games appeared to have been games that they brought with them and not the game provided by the restaurant.

\section{Personal technology and digital entertainment}

The presence of technology during the family dining experience was very prevalent. The researchers observed that it was common for a family to bring technology such as a tablet, an iPad or a handheld gaming system into the restaurant specifically for their child to use. For example, child-sized headphones that the child wore to independently watch a video playing on a tablet while they were eating. The use of some form of technology during the visit was observed for $40 \%$ of the children, with use averaging 14 minutes ( $30 \%$ of the total dining time). 


\section{Adults}

While sometimes adults used technology when dining with their child, the key time for adults to use their personal technology was while the child was playing in the indoor play area, with $70 \%$ of observed adults spending time using technology, such as a smart phone or a tablet, at this time. Of the $30 \%$ of adults that did not use technology while waiting for their children to play or eat, half of these adults used the time to talk to another adult in their party, while the other half watched the TVs that were mounted in the restaurant or read books or the free newspapers provided by the restaurant.

For most, any interaction with screen time came from time spent with personal screens (smart phones, tablets, iPads) that the customers brought with them into the restaurant. The restaurants had flat screen TVs playing 24/7 news channels in the restaurants, but engagement with the TVs was limited. Only $15 \%$ of adults and $5 \%$ of children were observed spending any time watching the restaurant TVs.

During the dining experience, $25 \%$ of the families included an adult who used their mobile technology to take at least one photo of the meal event, including photos of the food, photos of the child, selfies, and group photos. The use of technology to capture the dining experience was not unexpected, given the millennial consumer's love of photographing their food. It is estimated that as high as $69 \%$ of millennial consumers take a photo or video of their meal before eating (Maru/Matchbox, 2016).

Technoference, technology-based interference in parent-child interactions, is a growing part of the family dining experience. Of the 100 families observed dining, researchers noted that technoference appeared to be a frequent occurrence during family meals. Children's engagement in technology appeared to lead to less interaction with their parent(s), and when the adult was engaged in using technology, they appeared to be less responsive to the child.

\section{Child's Meal and Restaurant-Provided Toys}

Since toys are often criticized in the popular press for playing a potential role in influencing children to consume more fast food, field researchers were instructed to include in their structured field notes specific observations about the role that the free toy played in the family dining experience, both during the ordering process and during the dining experience.

In the restaurant, there were three options available to children that might be considered restaurantprovided toys: (1) free crayons and colouring sheets were available upon request to any customer, with no purchase requirement, (2) the child's meals came with a toy and (3) the child's meals came in a box that had games and images printed on the box for the child.

There was little use of the free crayons and colouring sheets. Only $7 \%$ of families used these, and that was only when on one of the field days a restaurant manager had walked around the dining area actively passing out sheets and crayons to families. No family was observed requesting these from the order counter, although the lack of observed use of these sheets and crayons may stem from a lack of awareness of their availability.

During the field research, the toys available in the restaurant were characters from a popular children's movie, in theatres at the time, which was one of the top 10 grossing box office movies of the year. While the restaurant layouts included an eye-level display of toys that accompanied the child's meal options, 
fewer than $5 \%$ of the children were observed looking at, or interacting with, the toy display either as a part of the ordering process or during the dining experience.

Nearly 7 in 10 families (68\%) purchased a dedicated child's meal, which included a free toy and a custom box for the meal. The distinctive packaging of the child's meal made it easy for the researchers to observe when this was purchased, and to see if the child interacted with the packaging. While there were games on the box for the child's amusement, only $20 \%$ of children spent any time playing or looking at the box. For most families, the meal was unpacked and the box was immediately set to the side. It was often used as a repository for garbage from the meal.

The inclusion of a toy in the child's meal did not mean that children were necessarily permitted to play with the toy during the restaurant visit. For $22 \%$ of the children, an adult removed the toy from the box and tucked it away out of sight (for example into a bag or purse) and the toy remained there during the entire visit.

For the $78 \%$ of children that did interact with the toy during their visit, researchers noted that for many families there appeared to be a rule or negotiation associated with when the child could play with the toy (for example, some parents could be overheard saying that the child could play with the toy only after they had eaten their meal). Of the children observed, $18 \%$ played with the toy before eating, $40 \%$ played with the toy while eating and $45 \%$ played with the toy after eating. These were not mutually exclusive moments, for example, some children played with the toy before, during and after the meal. Of those that played with the toy, on average, they played with the toy for 10 minutes (minimum 2 minutes, maximum 27 minutes).

\section{Family Behaviours}

\section{Third Place}

The restaurant appeared to serve the role of a 'third place' (a substitute home), with what seemed to be regular and local customers who were familiar with the specific location. The fast food restaurants appeared to provide neutral ground, where societal status did not seem to be very important and there was a casual hominess, in which customers treated the space as a home away from home as noted earlier.

For many families, the restaurant was used as a common meeting place, where they could socialize with other families. It was a place for the children to play together in the play room, while the adults interacted without the need to pay close attention to the children. A summary of the results from the enumerated family behaviours is illustrated in Figure 1.

Brembeck (2005), in a study of fast food restaurant meals in Sweden, has suggested that a 'proper' family meal in a fast food restaurant for many parents is an effortless way of upholding family life, and creating 'family' and 'home' in new ways. Thus, some of the behaviours of the families observed in this study, such as the presence of technology during meal times, should not necessarily be viewed as unique to a fast food restaurant, but today are potentially indicative of common family dining behaviours beyond fast food restaurants. 


\section{Family Interactions During Food Ordering}

During the ordering process, $69 \%$ of children remained with their adult, with varying degrees of involvement in the ordering process. Prior to ordering, $66 \%$ of adults spoke with the child at least once before placing the food order. While placing the order, $12 \%$ of children were involved in placing the order, speaking directly to the restaurant employee taking the order. The food ordering process was noted to be a very neutral experience overall, and fewer than $5 \%$ of the children were noted as being visibly unhappy (crying or yelling).

The demographics of the adults (number of adults, gender, and age) were examined to see whether specific subgroups were more likely to involve their child in the ordering process. No statistically significant subgroup differences were detected.

\section{Empirical Measurements of Family Ordering Times}

Researchers observed the families during lunch hours on Fridays, Saturdays and Sundays, as these days of the week reflect the busiest times for families in restaurants, and as such, the measured times could reasonably be expected to be on the high end of what a typical family might experience. Families visiting during non-peak times might have a faster ordering experience.

\section{Pre-order Time}

The average customer time, from the moment the family entered the restaurant to when they first spoke to the order taker, averaged 1 minute and 39 seconds. Customers spent a comparable amount of time regardless of party size, gender, ethnicity or number of children.

\section{Time to Place the Order}

The average order transaction time was 1 minute and 17 seconds. All observed attributes were analysed to determine which, if any, might influence order time. Three main elements were identified as statistically significant in impacting order time.

(i) Size of Party: As the number of people in the party increased, the amount of time to order increased. When there were two or more adults in the party, order time increased by an additional 19 seconds (+27\%). With parties of three of more children, order time increased by 41 seconds $(+53 \%)$.

(ii) Customer Age. As the observed age of the adults in the party increased, the length of time to order increased as well. Transactions with adults estimated to be under the age of 50 typically took 1 minute and 14 seconds, while transactions with adults estimated to be over the age of 50 , took an average of 1 minute and 28 seconds ( $+13 \%)$.

(iii) Ordering a Child's Meal Bundle. Including a child's meal (identified by the distinctive packaging) in the ordering process increased the average order time from 69 seconds to 82 seconds $(+19 \%)$.

\section{Time to receive the order}

The average wait time to receive a meal was 2 minutes and 53 seconds. No statistically significant subgroups based on observed attributes were identified. 


\section{Family Behaviours During Dining}

\section{Eating}

The ethnographic research was based on naturally occurring family visits, but the observed family groups did not necessarily order food for every individual in their party. Five percent of children did not have food that appeared to be ordered specifically for them and they were observed sharing food with an adult and $14 \%$ of adults did not appear to have ordered food for themselves. In addition, $14 \%$ of families brought food into the restaurant from an outside source and consumed that food in the restaurant (e.g., a box of donuts, juice boxes, plastic containers of cheerios cereal).

Often an adult unpackaged and/or arranged the food on the table for the family. For example, this included pulling the food out of the packaging, arranging it in front of the child, and on $32 \%$ of the occasions it included at least one time where an adult hand was feeding the child, for example holding the burger for them to bite or holding their drink cup for them. While there was a self-serve beverage fountain in the restaurant, only $11 \%$ of children were observed using it to fill their own drink cups.

The researchers observed that the adults frequently used this food set-up time to provide direction to the child on behaviour expectations, for example tucking a toy away before the child ate the food, or putting the packaging to the side and identifying it as a receptacle for waste.

Meal time did not appear to be a time for extensive conversations. Many of the families ate in near silence or with minimal interaction. Eating was automatic and appeared disengaged in nature. Often, dining occurred in stages. Either the child ate first, and then went to play while the adult(s) ate, or the adult(s) ate while the child played in the play room and later the child ate. Eating in stages often meant that when the child ate first, the parent later 'finished' the food the child left behind. Approximately one-third of the children ate at a different time than their parents. As a result of staggered eating times, modelling desirable eating behaviours is challenging (Ayadi and Bree, 2010).

Food tended not to be shared among family members, with one notable exception, which was the shared consumption of french fries, and the observed familial habits that seemed to accompany this. For some families, the communal approach to fry eating involved placing the fry order in the centre of the dining table, so that all members of the family had equal access to the fries. Some $37 \%$ of adults were observed eating fries from the child's order and $23 \%$ of the children were observed eating fries from the adult's food order. Taking food from family members that was not french fries was less frequent, with $28 \%$ of adults eating from the food ordered for the children (i.e., food that was not french fries), although this was often after the child declared themselves finished eating, and $12 \%$ of children were observed eating some of the non-french fry food that the adults had ordered. Often the taking of french fries from one another appeared to be in kind-hearted jest or a thoughtful way to share food without perceived injustice (for example a large order of french fries might have $50+$ french fries in it, making it easy to share a few fries with a family member without a perceptible loss of food).

Use of the Play Area

The restaurants included an indoor play area, with signage indicating it was meant for children age 3 to 12 years old. During the food ordering process, no children were observed to be playing in the indoor playground while their accompanying adult ordered food. 
While there was optional seating ( 2 tables and 4 chairs) inside of the indoor play room, where adults could sit and supervise the children as they played, these seats were most often empty. Rarely did adults move from the table they had dined at, into the indoor play area to watch their children closely. More often, there appeared to be an assumption that if the child was in the play area, no additional supervision was required. With the large glass windows on the interior of the indoor play area, there was visibility into the indoor play area from approximately one-third of the main dining area, however, the windows muted the sounds of the children.

Supervision of the children in the play room was minimal. While approximately two-thirds of the seating in the main dining area did not provide sight into the indoor play room, this lack of sight line did not appear to influence whether or not the child went into the play room. Most often, parents remained seated at the table in the main dining area, while children went to play in the indoor play area unsupervised.

The indoor play room was a strong draw for the children, with $65 \%$ of children spending time there and averaging 33 minutes in the play room (minimum 3 minutes to maximum 99 minutes). The approach to balancing play time and eating varied by family. Of the children that spent time in the play area, $55 \%$ spent time in the play area prior to eating and $36 \%$ went back and forth to the play area during the meal. Of the children that visited the play area, $81 \%$ of those children visited the play area after finishing their meal. Play was not limited to within the indoor play area as children were also observed conducting free play (neither on the climbing structure nor with a toy) during their visit, averaging 4 minutes of free play in the dining area in addition to time spent dining and in the indoor play area.

The researchers also noted that during the 10 days of field research, they observed two families who came to the restaurant for the express purpose of allowing their children to play in the indoor play area. During their visits, they ordered neither food nor drink from the restaurant. Field notes also included two families that spent so much time in the restaurant that they consumed two distinct meal orders during their one visit (a-breakfast and later a lunch), giving their children extended time to play both in the dining area and play area, between the meals.

\section{Other Activities}

While the child ate or played in the indoor playground, the adults were observed conducting a wide variety of activities that one might not associate with restaurant based activities but are reflective of how the fast food restaurant has taken on the role of a 'third space' for families. Observed activities included (but were not limited to): conducting a business meeting with a laptop, interviewing someone for a job, working on homework, playing chess, watching an entire movie on a tablet, sleeping on a bench, and clipping and filing fingernails.

\section{Field Notes}

Extensive field notes were gathered during the research. The field notes included a structured component in which researchers noted observations on technology, toy usage and dining behaviours as well as an unstructured component, where researchers recorded other observations, which were later grouped into themes during the analysis. An example of a field note from each of the broad categories identified from the research is included in Table 1. 
Conclusions

The study investigated the behaviours of families in fast food restaurants, both their ordering and inrestaurant dining experience. Twelve years ago, Brembeck (2005) suggested that fast food meals provide an opportunity for parents to have a 'proper' family meal with their children. Indeed, fast food restaurants appear to have taken on a 'third place' role for families, offering not only fast, and convenient dining, but also a public space in which to gather and spend time. Elements of how the observed families dined together may illustrate common behaviours in a sizeable proportion of today's family meals. The presence of technoference for personal entertainment had not yet become mainstream during the time that Brembeck studied families in fast food restaurants. The rise of technology has led to a shift in dining practices, such as the intrusion of technology during the meal. With food consumed away from home on the rise, understanding how families dine outside of the home will continue to grow in importance, especially in terms of technology, toys and family time.

The main results indicate that:

- Technology

- While mobile technology was largely absent during the ordering process, once the families moved to the dining area, both children and adults were frequently observed using technology in the restaurant. As a result, technoference appeared to be present during the family dining experience for many families in the fast food restaurants, with $40 \%$ of children using technology while with their family.

- Toys

- Children spent more time playing with technology they brought from home (14 minutes) than playing with a restaurant provided toy (10 minutes).

\section{- Family Time}

- Meal ordering was a quick and functionally driven experience, with minimal adult/child interaction, averaging less than 6 minutes from the time the family entered the restaurant to when they had received their complete food order.

- French fries provided a shared dining experience for families.

- While the children spent time in the indoor playground (average 33 minutes), adults used the time for independent activities (70\% used their smart phone).

- The fast food restaurant was treated as a 'third place', with many observed activities unrelated to traditional restaurant dining.

\section{Limitations and Future Perspectives}

Canadian food dining culture may be different from that observed in other countries, and as such, these results have to be considered within the Canadian context. Canadians have one the highest global rates of smart phone usage and internet connectivity and may, therefore, be a bellwether of future consumer behaviour in countries with rapidly growing smart phone penetration, as well as countries with a similar frequency of family fast food consumption. What is unknown is whether this change in behaviour resulting from the prevalence of personal technology has plateaued or if it will continue to increase in the coming years. 


\begin{abstract}
A limitation of this study is that it focused exclusively on in-restaurant behaviours. There is no visibility of the parent/child interaction prior to entering the restaurant, nor visibility to behaviours after they leave the restaurant. Therefore, the toy and associated e-game may play a larger role than what was observed in-restaurant.

This research relied on observed behaviours and on the subjective abilities of the ethnographers. Future research considerations should include follow-up interviews with families to provide a greater depth of information about their experience. Other future research should also include restaurant locations without an indoor play area, to examine if this would change the amount of time spent by children and adults using personal mobile technology.
\end{abstract}




\section{References}

Anzman-Frasca, S., Folta, S.C., Glenn, M.E., Jones-Mueller, A., Lynskey, V.M., Patel, A.A., Lisa, L.T. and Lopez, N.V. (2017), "Healthier children's meals in restaurants: an exploratory study to inform approaches that are acceptable across stakeholders", Journal of Nutrition Education and Behavior, Vol. 49 No. 4 , pp. 285-295.

Australian Bureau of Statistics, (2006), "Australian social trends", available at: http://www.abs.gov.au/AUSSTATS/abs@.nsf/DetailsPage/4102.02006?OpenDocument (accessed 30 July, 2017)

Ayadi, K. and Bree, J. (2010), "An ethnography of the transfer of food learning within the family", Young Consumers, Vol. 11 No. 1, pp. 67-76.

Bakan, J. (2012), Childhood Under Siege: How Big Business Targets Your Children. Simon and Schuster, New York, NY.

Boutelle, K. N., Fannin, H., Newfield, R. S. and Harnack, L. (2011), "Nutritional quality of lunch meal purchased for children at a fast-food restaurant", Childhood Obesity, Vol. 7 No. 4, pp. 316-322.

Brembeck, H. (2005), "Home to McDonald's: upholding the family dinner with the help of McDonald's", Food, Culture and Society, Vol. 8 No.2, pp.215-226.

Castro, I. A., Williams, C. B., Madanat, H., Pickrel, J. L., Jun, H. J., Zive, M., Gahagan, S. and Ayala, G. X. (2016), "Food ordering for children in restaurants: multiple sources of influence on decision making", Public Health Nutrition, Vol. 19 No. 13, pp. 2404-2409.

Catalyst (2015), "With growth comes change: the evolving mobile landscape in 2015", available at: http://catalyst.ca/2015-canadian-smartphone-market/ (accessed 30 July 2017)

Chou, C. Y. and Liu, H. R. (1999), "Simulation study on the queuing system in a fast-food restaurant", Journal of Restaurant and Foodservice Marketing, Vol. 3 No. 2, pp. 23-26.

Iqbal, Q., Whitman, L. E. and Malzahn, D. (2012), "Reducing customer wait time at a fast food restaurant on campus", Journal of Foodservice Business Research, Vol. 15 No. 4, pp. 319-34.

Maru/Matchbox (2016), "The future of food. Are you ready for the millennials?", available at: https://marumatchbox.com/resources/Ip-the-future-of-food-are-you-ready-for-the-millennials/ ( accessed 30 July, 2017)

McDaniel, B.T. (2013), "Technoference: Everyday intrusions and interruptions of technology in couple and family relationships", in Bruess, C.J. (Ed.), Family Communication in the Age of Digital and Social Media, Peter Lang Publishing, New York, NY, pp. 228-244.

McDaniel, B.T. and Radesky, J.S. (2017), "Technoference: Parent distraction with technology and associations with child behavior problems", Child Development, doi: 10.1111/cdev.12822 [Epub ahead of print]

Office for National Statistics (2016), "Statistical bulletin: Family spending in the UK: financial year ending March 2016", available at: 
https://www.ons.gov.uk/peoplepopulationandcommunity/personalandhouseholdfinances/expenditure/ bulletins/familyspendingintheuk/financialyearendingmarch2016 (accessed 30 July, 2017)

Oldenburg, R. (1989), The great good place: Café, coffee shops, community centers, beauty parlors, general stores, bars, hangouts, and how they get you through the day, Paragon House Publishers, New York, NY.

Otten, J.J. (2014), Food Marketing: Using Toys to Market Children's Meals. Healthy Eating Research, Minneapolis, MN, available at: http://healthyeatingresearch.org/wpcontent/uploads/2014/07/her marketing toys AUGUST 14.pdf (accessed 30 July, 2017)

Otten, J.J., Saelens, B.E., Kapphahn, K.I., Hekler, E.B., Buman, M.P., Goldstein, B.A., Krukowski, R.A., O'Donohue, L.S., Gardner, C.D. and King, A.C. (2014), "Impact of San Francisco's toy ordinance on restaurants and children's food purchases, 2011-2012", Preventing Chronic Disease, Vol. 11, p.E122.

Pew Research Centre (2017), "Pew Research Center analysis of National Center for Health Statistics data", available at: http://www.pewresearch.org/fact-tank/2017/01/03/more-than-a-millionmillennials-are-becoming-moms-each-year/ (accessed 30 July, 2017)

Radesky, J.S., Kistin, C.J., Zuckerman, B., Nitzberg, K., Gross, J., Kaplan-Sanoff, M., Augustyn, M. and Silverstein, M. (2014), "Patterns of mobile device use by caregivers and children during meals in fast food restaurants", Pediatrics, Vol. 133 No. 4, doi:10.1542/peds.2013-3703

Rydell, S. A., Harnack, L. J., Oakes, J. M., Story, M., Jeffery, R. W., and French, S. A. (2008), "Why eat at fast-food restaurants: reported reasons among frequent consumers", Journal of the American Dietetic Association, Vol. 108 No.12, pp. 2066-2070.

Sifferlin, A. (2015), "Research: 6-month-old babies are now using tablets and smartphones", Time (Health), 25 Apr, available at: http://time.com/3834978/babies-use-devices/) (accessed 30 July, 2017)

Statista (2017), "Is your cellphone a smartphone, such as an iPhone, a Blackberry or the like?" available at: https://www.statista.com/statistics/539409/smartphone-ownership-by-age-in-selected-countries/) (accessed 30 July, 2017)

Statistics Canada (2015), "Average household food expenditure, (Ontario)", available from: http://www.statcan.gc.ca/tables-tableaux/sum-som/l01/cst01/famil132g-eng.htm (accessed 30 July, 2017)

United States Department of Agriculture (USDA) (2016), “Food expenditures - United States Department of Agriculture, Economic Research", available at: https://www.ers.usda.gov/data-products/foodexpenditures.aspx (accessed 30 July 2017)

United States Department of Labour (USDL) (2015), "Glossary - consumer expenditure survey", available at: https://www.bls.gov/cex/csxgloss.htm (accessed 30 July 2017)

VicHealth (2015), "Fame and Shame awards: Not so happy: McDonald's not lovin' Fame and Shame awards". 8 Dec. 2015. [On-line] available at: https://www.vichealth.vic.gov.au/media-andresources/media-releases/not-so-happy-mcdonalds-not-lovin-fame-and-shame-awards (accessed 30 July 2017) 
Wang, Y., Deng, Q. and Ji, S. (2017), “Applying third place theory in mobile social media research: The physical-virtual integration", CONF-IRM 2017 Proceedings. 4, available at:

http://aisel.aisnet.org/confirm2017/4 (accessed 30 July 2017) 